\title{
Elements of Programme Music in the Instrumental Works of the Late Period by Oleg Meremkulov (the Case of the Symphony Concerto for Cello, Piano and Orchestra)
}

\author{
Natalia M. Naiko* \\ Dmitry Hvorostovsky Siberian State Academy of Arts \\ Krasnoyarsk, Russian Federation
}

Received 10.10.2021, received in revised form 10.12.2021, accepted 18.01.2022

\begin{abstract}
This article reveals some aspects of the creative identity and later works of the greatest Krasnoyarsk composer O. Meremkulov. To understand the artistic aspirations and originality of O. Meremkulov's works, his Symphony Concerto for Cello, Piano, String Orchestra, Percussion and Wind Ensemble (2015) is an illustrative piece of art. The concerto genre was conceived by the composer as a composition showing the essential problems of human existence, preserving the modus of a personal statement «in the first person». This has led to the introduction of epigraphs and programme titles of parts that not only tune the listener in a certain way, but are elements of concept and means of realising the author's intentions.

The musical analysis regarding the main intonational characteristics of all parts of the concerto, their relations, aspects and orientation of the development of musical thematism are correlated with possible interpretations of titles and epigraphs. This made it possible to come to the conclusion about the original programme music of the concerto.

It is revealed by a combination of means functioning at various levels, addressing the sensations of different modalities, individual experience, cultural memory, as well as activating associative thinking and figurative representations. Not only part titles and epigraphs work in this respect, but also the author's remarks introduced into the musical score and audio records with natural sounds during the performance. Programme music is also recognised in the process of thematic transformations that reflect the orientation of the Hero's emotional experiences clarifying the essence of a certain image or reproducing a chain of events related to a certain plot.

It has been suggested that this plot bizarrely refracts in the composer's mind the real events experienced by him during different periods of life, sprouted into the subjective perception and understanding of artistic images of world culture. In his dialogue with the authors of past centuries, the composer reached a new level of generalisation, thereby capturing his ideas and feelings in an intonational form. This has led to the originality and unique harmony of the Symphony Concerto.
\end{abstract}

(C) Siberian Federal University. All rights reserved

* Corresponding author E-mail address: mikinai@yandex.ru, mailto: mikinai@ya.ru 
Keywords: O. O. Meremkulov, symphony concerto, works of Siberian composers, modern Russian instrumental concerto, programme music, Shakespeare's imagery in symphonic music.

Research area: musical art.

Citation: Naiko, N.M. (2022). Elements of programme music in the instrumental works of the late period by Oleg Meremkulov (the case of the symphony concerto for cello, piano and orchestra). J. Sib. Fed. Univ. Humanit. soc. sci., 15(1), 75-84. DOI: 10.17516/1997-1370-0877

\title{
Элементы программности
}

\section{в инструментальных сочинениях позднего периода Олега Меремкулова \\ (на примере Концерта-симфонии для виолончели, фортепиано и оркестра)}

\section{Н.М. Найко}

Сибирский государственный институт искусств

имени Дмитрия Хворостовского

Российская Федерачия, Красноярск

\begin{abstract}
Аннотация. В статье раскрываются некоторые черты творческого облика крупнейшего красноярского композитора О. Меремкулова и особенности его поздних сочинений. Для постижения художественных устремлений и своеобразия творчества О. Меремкулова показательным произведением является Концертсимфония для виолончели, фортепиано, струнного оркестра, ансамбля духовых и ударных (2015). Жанр концерта мыслился композитором как род сочинения, позволяющий отображать сущностные проблемы человеческого бытия, сохраняя модус личностного высказывания «от первого лица». Это обусловило введение эпиграфов и программных заголовков частей, которые не просто настраивают слушателя на определенный лад, а являются элементами замысла и средствами реализации авторских намерений.
\end{abstract}

Данные музыкального анализа, касающиеся основных интонационных характеристик всех частей концерта, их взаимосвязей, особенностей и направленности развития музыкального тематизма, соотносятся с возможными интерпретациями заголовков и эпиграфов. Это позволило прийти к заключению о своеобразной программности концерта.

Она раскрывается совокупностью средств, функционирующих на различных уровнях, обращенных к ощущениям разных модальностей, к индивидуальному опыту, культурной памяти, активизирующих ассоциативное мышление, образные представления. В указанном направлении действуют не только заголовки частей и эпиграфы, но и авторские ремарки, введенные в партитуру, привлечение во время исполнения музыки фонограмм с природными звуками. Программность угадывается также в процессе тематических трансформаций, отображающих направленность эмоциональных переживаний героя, проясняющих суть какого-то 
образа или воспроизводящих цепь событий, соотносящихся с неким сюжетом. Высказано предположение, что в данном сюжете реальные события, пережитые композитором в разные периоды жизни, причудливо преломились в его сознании, проросли в субъективном восприятии и осмыслении художественных образов мировой культуры. В диалоге с авторами прошлых веков композитор вышел на новый уровень обобщения, запечатлев свои идеи и чувства в интонационной форме. Это обусловило оригинальность и уникальную органичность Концертасимфонии.

Ключевые слова: О.О. Меремкулов, концерт-симфония, творчество сибирских композиторов, современный отечественный инструментальный концерт, программность, шекспировские образы в симфонической музыке.

Научная специальность: 17.00.02 - музыкальное искусство.

\section{Введение в проблему исследования}

Последнее двадцатилетие жизни красноярского композитора Олега Меремкулова (1935-2019) отмечено ярчайшим творческим взлетом. Он прожил долгую жизнь, но тем не менее окружающие восприняли его уход как преждевременный - зрели оригинальные идеи, ждали завершения уже начатые партитуры, велись переговоры о поездках, планировались премьеры, намечалось приведение в порядок архива, издание некоторых сочинений (Naiko, 2020).

В новом тысячелетии композитором был создан ряд произведений, отличающихся особой глубиной замысла: Двойной концерт для гуслей звончатых, виолончели и симфонического оркестра (2008) и Концерт-прелюдия (2010), на основе которых возникла Диптих-симфония для виолончели и фортепиано с оркестром (Naiko, 2018); Концертные вариации «Празднества» для трех гуслей и одного исполнителя (2014), Концерт для баяна и симфонического оркестра в 3 частях ${ }^{1}$ (2014), Поэма гнева и любви (Героическая поэма) на стихи Анны Ахматовой для симфонического оркестра, детского хора и меццо-сопрано (2014), Концерт-симфония для виолончели и фортепиано с оркестром (2014).

Буквально в последнее пятилетие жизни осуществлялась работа над несколькими крупными сочинениями, среди них: Концерт для фортепиано с оркестром, Концерт

\footnotetext{
1 Он мыслился автором также как концерт для органа и симфонического оркестра.
}

для фагота и камерного оркестра ${ }^{2}$, Баллада для баритона и фортепиано «Возвращение», Реквием «Памяти нетленный след» для хора, солистов и симфонического оркестра. Была начата «Песнь торжествующей любви» $3^{3}$ (по одноименной повести И.С. Тургенева).

Подобная интенсивность наряду с содержательной глубиной и индивидуальным своеобразием художественных решений свидетельство пика личностного и творческого развития.

По мысли Юнга, для достижения уровня личности требуется вся человеческая жизнь со всеми ее биологическими, социальными и психологическими аспектами. «Мы не знаем наперед, какие дела и злодеяния, какая судьба, какое добро и какое зло содержатся в нас, и только осень покажет, что было зачато весною; лишь вечером станет ясно, что началось утром» (Iung, 1998).

О. Меремкулов в свою «осеннюю» пору, видимо, осознавал, что ни один даже самый неожиданный и причудливый зигзаг его жизненного пути не был случаен, никакая встреча не оказалась напрасной. Все проросло, все сказалось на его душевной организации; все, что довелось пережить, отозвалось, наложило отпечаток на восприятие и понимание мира.

\footnotetext{
2 В одной из версий неоконченной партитуры он обозначен автором как Концерт-поэма для фагота и камерного оркестра с участием сопрано-соло.

3 Партитура, датированная июнем 2017 г., обрывается на 109-м такте.
} 
О. Меремкулов был наделен не только музыкальным, но и литературным, поэтическим даром. Возможность получить композиторское образование ему предоставилась относительно поздно. Но вполне вероятно, что для профессионального становления музыканта-творца было необходимо сначала воспитать в себе особую чуткость к слову, погрузиться в художественный мир творений Ф. М. Достоевского (о чем, будучи студентом филфака, он писал дипломную работу), осмыслить многое вместе с его героями, примерить на себя их критические жизненные ситуации, взлеты, падения, страдания.

Вспоминая события детства или юности, годы учебы в Ферганском педагогическом институте и в Горьковской консерватории, перечитывая шедевры отечественной и мировой литературы, он все более явственно ощущал свою неслучайность и причастность к тому, что было и 60 , и 160 лет, и несколько веков или даже тысячелетий тому назад. Обращаясь к опыту прошедших эпох, претворяя традиционное, композитор во многом оказывается первооткрывателем, подтверждая своим творческим расцветом утверждение психологов о том, что человек становится личностью только тогда, когда он «ощущает глубинную связь с прошлыми поколениями, со всем человечеством» (Starcheus, 2012).

Тем, кому довелось общаться и беседовать с О. Меремкуловым, запомнилась манера его речи - импульсивная, порывистая, с обилием аллюзий, «брошенных» мыслей, фраз, как будто завершающихся многоточием. Эта манера выдавала пылкого, темпераментного, увлекающегося и вместе с тем утонченного, деликатного, чрезвычайно щепетильного и ранимого человека с богатым воображением, с очень динамичными внутренними переживаниями. Его романтическая устремленность к возвышенному идеалу сочеталась с ироничностью как средством защиты от окружающей пошлости и неизбежных разочарований. Бурлящая лава не всегда осознаваемых впечатлений, эмоциональных реакций, влечений, ассоциаций нуждалась в слове как средстве фиксации, запечатления, постижения, осмысления внутренних процессов, происходивших в глубинах собственной психики и питавших творческие замыслы.

Созидательный потенциал О. Меремкулова реализовался, помимо музыкальной композиции, в литературном творчестве в сочинении стихотворений, в подготовке либретто для музыкально-драматических сцен «Бесы» по произведениям Ф. Достоевского. При воплощении масштабных вокально-инструментальных проектов, обращаясь к поэтическим текстам других авторов, он нередко преобразовывал их, вносил существенные изменения, исходя из своих художественных намерений.

Активность художественного сознания композитора находила свое выражение также в переработке опыта мастеров предшествующих эпох, в переосмыслении сложившихся в классико-романтическую эпоху жанров. Его творческий процесс, захватывая, подчиняя все сферы личной жизни, все человеческие проявления, естественно распространялся и на поиск жанрового определения для каждого нового опуса, чему композитор придавал большое значение.

\section{Постановка проблемы}

Даже при простом перечислении обращает на себя внимание тот факт, что в последние годы О. Меремкулов создавал в большинстве своем концерты для солирующих инструментов с оркестром. Отчасти их замыслы были так или иначе инициированы конкретными исполнителями - виолончелистом Михаилом Курицким, баянистом Сергеем Найко, пианистом Денисом Приходько, гусляром Павлом Лукояновым.

По выражению В.В. Медушевского, «жанровая сторона музыки свое разнообразие черпает из бездонности обстоятельств жизни и состояний души (Medushevskii, 2015). Концерт в творчестве Меремкулова - концепционный жанр, не случайно два концерта (Двойной концерт для гуслей звончатых, виолончели и симфонического оркестра и Концерт-прелюдия) были объединены в Диптих-симфонию. А Кон- 
церт для виолончели и фортепиано с оркестром именовался автором и как Концертсимфония.

Концерт, очевидно, мыслился композитором как род сочинения, позволяющий отображать глубинные, сущностные проблемы человеческого бытия, сохраняя модус личностного высказывания «от первого лица». Личностное меремкуловское как «носителя мироотношения» (Korman, 1974) - в страстности натуры, в погруженности в многомерность тончайших ассоциаций, в интенсивном проживании скрытых смыслов, в эмоциональной насыщенности музыкального интонирования.

Закономерно, что иногда композитор вводит программные заголовки частей, a в ряде сочинений фигурируют эпиграфы. Предполагалось, что эпиграфы будут озвучиваться непосредственно перед исполнением музыки. На премьерах Концерта для баяна и симфонического оркестра и Концерта-симфонии для виолончели, фортепиано, струнного оркестра О.О. Меремкулов зачитывал их сам.

Например, I части Концерта для баяна и симфонического оркестра предпосланы строки:

Приближен к тайнам мирозданья, начавший долгий путь в ночи.

(Из старых рукописей $\left.{ }^{4}\right)$

II часть предваряется следующим поэтическим текстом:

Хоть вой, хоть лезь из кожи вон не возродится в мире связь времен. Старуха та с заточенной косой так разгулялась в ярости лихой, что красной сделалась луна,

безумные пророча времена.

Эпиграфом к Концерту для фагота и камерного оркестра служит такой диалог:

- Откуда, река, тыл катишь волны свои величавые?

- Из вечности, отрок, из вечности.

- Куда ж устремляешь ты бег свой, не зная покоя?

- В вечность, недогадливый, в вечность.

\footnotetext{
4 В другой копии концерта в скобках содержится указание
} на неизвестного автора IX в.
В другой копии он изложен несколько иначе:

- Откуда, река, ты катишь волны свои величавые?

- Из вечности, отрок, из вечности.

- А куда ты несешься, в стремительном беге сметая преграды?

- В вечность, странник печальный, в вечность.

Наличие вариантов эпиграфов в разных копиях нот позволяет предположить авторство самого композитора.

Обращение в эпиграфах к вневременно́й, актуальной для всех поколений тематике свидетельствует о том, что все крупные сочинения О.О. Меремкулова, созданные в последний период творчества, так или иначе связаны с осмыслением художником человеческой жизни и судеб культуры.

\section{Методология}

Конечно, для постижения образносодержательного плана названных сочинений необходимо углубленное изучение разворачивающихся в них интонационных процессов. Поэтому ведущими методами исследования стали интонационный анализ и жанровый анализ тематизма, соединенные с системным подходом. Вместе с тем, учитывая специфику дарования О. Меремкулова и особенности протекания у него творческого процесса, мы приходим к пониманию того, что заголовки и эпиграфы в его музыкальных композициях не просто настраивают слушателя на определенный лад, а являются элементами замысла и средствами реализации авторских намерений. Их анализ способен многое приоткрыть. Исходя из этого используется и метод интерпретации.

Благодатным материалом для изучения обозначенной проблемы оказывается Концерт-симфония для виолончели, фортепиано, струнного оркестра, ансамбля духовых и ударных. Мировая премьера этого сочинения состоялась 10 января 2015 г. в Москве, в зале РАМ имени Гнесиных. Солистами выступили: заслуженный артист Российской Федерации Михаил Курицкий (виолончель), лауреат международных 
конкурсов Денис Приходько (фортепиано). Симфоническим оркестром Министерства обороны России дирижировал заслуженный артист Российской Федерации Борис Ворон.

\section{Обсуждение}

Концерт-симфония содержит четыре части. Первая часть озаглавлена автором «Боль». Чувство боли всегда характеризуется субъективным, эмоционально-личностным содержанием. И оно передано в музыке психологически тонко, динамично, но вместе с тем с высокой степенью обобщенности.

Понятие боли мы связываем с мучительным переживанием страдания, которое может быть вызвано крушением идеалов и торжеством пошлости, низостью и подлостью окружающих людей, предательством, потерей близких, осознанием несправедливости, непобедимости зла, недостижимости счастья, невозможности вернуть то, что было дорого, но утрачено, - словом, любыми аспектами дисгармоничности человеческого бытия и трагедийностью человеческой истории.

Особенностью всей циклической композиции и конкретно первой части оказывается интонационная общность всего музыкального материала. И по горизонтали, и по вертикали ведущая конструктивная роль принадлежит тематическому «комплексу Боли», включающему в себя малую секунду, большую септиму (как ее обращение), квинту, тритон. Можно сказать, что все темы производны от основной, выступая ее свободными вариационными трансформациями, в чем проявляется принцип монотематизма. Благодаря ему в музыке запечатлевается тонкая психологичность и динамика эмоциональных состояний.

Вторая часть - «Две мимолетности» представляет собой своеобразный слитный двухчастный цикл из контрастных частей, или контрастно-составную форму.

В данном случае важны не только аналогии с «Мимолетностями» С. Прокофьева или Г. Банщикова, общность смыслового поля, принадлежность к культурной тради- ции, но и указание на быстротечность запечатленного в музыке момента, его преходящесть, эфемерность в контексте Вечности.

«Две мимолетности» выполняют в цикле функцию жанровой части, объединяя скерцо и вальс.

Мимолетность I (allegretto scherzando) снабжена эпиграфом, в котором в символическую форму облечен мотив игры всесильного рока с человеческой жизнью:

\section{Неведомая сила}

неведомо куда,

едва не разрывая паруса,

несет, смеясь, мою ладью.

Этот раздел выстроен как свободные вариации, которые группируются по принципу трехчастной формы. С другой стороны, прослеживается единая линия общего нарастания, при котором раскрываются грани демонического пляса (по типу «плясок смерти»). Первая Мимолетность разомкнута, вторая Мимолетность вступает attacca.

Заголовок Мимолетности II «Этот старый забытый вальс» естественно вызывает ассоциации с «Забытыми вальсами» Ф. Листа, запечатлевшего в своей музыке, неуловимые, но манящие поэта образы прошлого, процесс их припоминания, кристаллизации в сознании. У О. Меремкулова это воспоминания о чем-то очень дорогом, но безвозвратно ушедшем, возможно, связанным с детством или юностью. Отсюда не только теплый лирический тон и некоторая элегичность, но и особенности самого тематизма, синтаксиса, процесса формообразования «размытость», неотчетливость очертаний, «фрагментарность» формы, а также инструментовка с повышенным значением солирующих тембров.

Третья часть названа композитором «Несколько страниц Шекспира». Эпиграфом к ней служит фрагмент диалога Гамлета с могильщиком из 1-ой сцены 5-го акта ${ }^{5}$ «Трагической истории о Гамлете, принце датском» У. Шекспира:

- Говорят, у Гамлета рассудок помутился..

\footnotetext{
5 Переводчик не известен, возможно, это вольный пересказ самого О.О. Меремкулова.
} 
- Да неужели? И на какой же почве?

- Конечно, на нашей, на датской ${ }^{6}$.

С одной стороны, очевидно, нет оснований искать сюжетную основу музыки этой части или расценивать ее как звуковую иллюстрацию какого-либо фрагмента трагедии Шекспира. Эпиграф, скорее, служит своего рода смысловым контрапунктом, концентрированно выражающим идейный и эмоциональный накал рассказанной У. Шекспиром истории «о подлинном благородстве и невозможности его существования в этом мире», знаком предельной меры взаимного отторжения Героя, чьи нравственные и духовные ориентиры, по словам Ольги Гордеевой, непомерно высоки, и общества, в котором он живет (Gordeeva, 2016).

С другой стороны, образ Гамлета, продолжающий свою историю как общекультурный символ и в наше время, для композитора был наполнен глубоко личным смыслом.

Думается, что О. Меремкулов, будучи страстной натурой, обладавший пылкой фантазией, гипертрофией чувства, эмпатийностью, склонностью к идеализации, чему неизбежно сопутствовали разочарования, наделенный талантом художника переступать грань между реальностью и воображением, неоднократно погружался в «параллельный» мир шекспировской трагедии, проживая ее эпизоды и испытывая на себе ее мощное напряжение. «Вопрос Гамлета» - это и его вопрос.

Третья часть возвращает образы первой части, но в ином - гораздо более значительном, едва ли не вселенском - масштабе. Здесь вновь воплощается переживание боли, однако охватившее не только Героя, но и окружающее пространство, словно вся природа неистовствует и даже «камни вопиют».

Очевидно, этим и объясняется введение в партитуру фонограмм со звуками надвигающейся грозы и грозы, превращающейся

\footnotetext{
6 Во время премьеры, прошедшей в Москве 10 января 2015 г., автор зачитывает последнюю строку эпиграфа иначе, чем написано в партитуре: «на нашей, милорд, на датской».
}

в разбушевавшуюся стихию, раскатов грома, ливня, крика хищной птицы и ремарок con fuoco, furioso.

При том что главенствующими качествами музыкальной формы являются процессуальность и динамизм, в постоянном обновлении тематического материала прослеживаются определенные закономерности, некая сюжетность. Уникальная интонационная фабула (термин И. А. Барсовой: Barsova, 1975) определяет и своеобразие композиции рассматриваемой части. Эпиграф вкупе с характеристиками собственно интонационного процесса наталкивает нас на мысль о том, что здесь основополагающее значение имеет сюжетная направленность шекспировской трагедии. Как следствие, образуется сквозная, «открытая» форма.

IV часть называется Silentium, что переводится с латыни как «Молчание».

Нет никаких данных для суждения о том, как возник такой заголовок - имел ли в виду автор музыки стихотворение Ф. Тютчева (датируемое 1830 г.) или О. Мандельштама (1910 г.), литературоведческие толкования которых значительно расходятся. Не известно, какие из поэтических идей были близки композитору.

Возможно, что импульсом послужило Silenzio для баяна, скрипки и виолончели Софии Губайдулиной (1991) или финальная часть с названием Silentium Двойного концерта Tabula Rasa для двух скрипок соло, подготовленного фортепиано и камерного оркестра (1977), принадлежащего перу Арво Пярта.

Комментируя название стихотворения Ф. Тютчева Silentium!, Татьяна Грант раскрывает несколько содержательных граней этого литературного шедевра. Она допускает его понимание в качестве поэтического призыва хранить тайну движений души, загадочную полноту невысказанной мысли («Молчи, скрывайся и таи // И чувства, и мечты свои»); либо в качестве выражения вынужденной «немоты» поэта, его символического протеста «против пошлости «наружного шума», мира обыденного сознания»; либо как своеобразный вариант 
воплощения романтического мотива одиночества, идеи невозможности истинного и абсолютного взаимопонимания между людьми («Другому как понять тебя?»); или же как запечатление бессилия слова для передачи внутренних движений души, сложных человеческих чувств и переживаний («Мысль изреченная есть ложь») (Grant, 2011).

Учитывая, что для музыки Меремкулова в целом характерна скрытая или явная программность, обусловленная как спецификой его мышления, так и стремлением композитора задать направление слушательскому восприятию, обозначить, хотя не прямо, но опосредованно, «иносказательно», свою позицию, все отмеченные Татьяной Грант нюансы значения слова Silentium актуальны для понимания IV части данного Концерта-симфонии.

Исходя из особенностей драматургии и трагической «развязки» предшествующей - третьей - части, где музыкальными средствами вполне явственно обозначена ситуация смерти, заголовок Silentium можно воспринимать и как выражение неизвестности и немоты, постигающей человека у последней черты, у предела жизни.

Думается, что неисчерпаемость смыслов, многомерность являются неотъемлемыми качествами любого выдающегося художественного произведения. Возможно, что при прослушивании и детальном анализе финала Концерта-симфонии О. Меремкулова будут выявляться все новые и новые смысловые оттенки. Основанием для них служит, в первую очередь, собственно направленность интонационно-тематических процессов.

Финал выполняет, по сути, функцию коды всего цикла, подводящей итог процессу образно-интонационного развития. Его генеральной идеей является постепенное изживание, рассеивание боли, выход за пределы «Я», за пределы обусловленных субъективным опытом эмоций и суждений, прикосновение к природной чистоте, растворение в бесконечном просторе.

Это обусловило постепенное изменение интонационных характеристик - снижение мелодической и гармонической напряженности, повышение роли диатонических мотивов, «природных» тембров духовых инструментов, фактурную разреженность, значение сольных фрагментов разных инструментов.

\section{Заключение}

На основании анализа концерта можно прийти к заключению о значении особого рода программности, которая раскрывается совокупностью средств всякого рода, действующих на различных уровнях, обращенных к ощущениям разных модальностей, к индивидуальному опыту, культурной памяти, активизирующих ассоциативное мышление, образные представления. В этом направлении действуют заголовки частей и эпиграфы, авторские ремарки, введенные в партитуру, привлечение во время исполнения музыки фонограмм с природными звуками. Программность угадывается и, собственно, в процессе тематических трансформаций, отображающих направленность эмоциональных переживаний героя, либо проясняющих суть какого-то образа, или воспроизводящих цепь событий, соотносящихся с неким сюжетом.

Можно предположить, что в этом сюжете реальные события, пережитые O. Meремкуловым в разные периоды его жизни, причудливо преломились в его сознании, проросли в субъективном восприятии и осмыслении художественных образов мировой культуры, и, поднявшись в диалоге с авторами прошлых веков на новый уровень обобщения, запечатлелись в интонационной форме.

Как полагает М. Г. Арановский, замысел симфонии выходит в экстрамузыкальную сферу и существо жанра заключено «... именно в установлении связей между симфоническими и реальными процессами» (Aranovskii, 1979). Меремкуловское «откровение о мире» обусловило оригинальность и уникальную органичность произведения, представшего самобытной смысловой вселенной (Serebryakova, 2017) 
Части цикла последовательно воплощают авторскую концепцию, образуя слитно-циклическую или контрастносоставную форму. Ее единство достигается действием принципа монотематизма, тесно связанного с методом производного контраста ${ }^{7}$, и свободной вариационностью, обеспечивающей яркую индивидуальность каждой части.

Непрерывное становление в крупных масштабах позволяет говорить о явлении

\footnotetext{
7 Который, как пишет К. Зенкин, по своей природе является симфоническим (Zenkin, 2005).
}

подлинного симфонизма как его понимал Б. В. Асафьев: «Симфонизм - творческое постижение и выражение мира чувств и идей в непрерывности музыкального тока» (Asaf'ev, 1972), мышление музыкой (как «непрерывность музыкального сознания»), осуществляющееся изнутри самой же музыки, а не при ее помощи. О. О. Меремкулов предстает перед нами в качестве крупнейшего симфониста в современной отечественной музыкальной культуре, сочетающего качества новатора и продолжателя традиций Ф. Листа, Г. Малера, Д. Шостаковича.

\section{Список литературы / References}

Aranovskii M. G. Simfonicheskie iskaniya. Problema zhanra simfonii v sovetskoj muzyke 1960-1975 godov. Issledovatel'skie ocherki. [Symphonic searches. The problem of the symphony genre in Soviet music of 1960-1975. Research essays.] Leningrad: Sovetskii kompozitor [Soviet composer], 1979. $287 \mathrm{p}$.

Asaf'ev, B.V. (1972). O muzyke Chaikovskogo [About Tchaikovsky's Music]. Leningrad, Muzyka, $376 \mathrm{p}$.

Barsova, I.A. (1975). Simfonii Malera [Mahler's Symphonies]. Moskva, Sovetskii Kompozitor, 496 p.

Gordeeva, O. (2016). Gamlet. Uil'yam SHekspir [Hamlet. William Shakespeare] https://www.livelib. ru/review/683295-gamlet-uilyam-shekspir (accessed 20 August 2021)

Grant, T. (2011). Literaturny dnevnik. Stikhi Tyutcheva [The Literary Diary. Tyutchev's Poems]. https://stihi.ru/diary/lilith6/2011-12-24 (accessed 20 August 2021)

Zenkin, K. (2005). K voprosu o simfonizme [On Symphonism], In Muzykal'naya kul'tura i iskusstvo: nablyudeniya, analiz, rekomendacii [Musical culture and art: observations, analysis, recommendations]. $5,17-33$.

Korman, B.O. (1974). Opyt opisaniya literaturnykh rodov v terminakh teorii avtora (subyektivnyi uroven) [An attempt to describe literary types using the theory of an author (subjective level)]. Problema avtora $\mathrm{v}$ hudozhestvennoy literature - Trudy Udmurtskogo gosudarstvennogo universiteta pyatidesyatiletiya SSSR [The problem of an author in fiction literature - Proc. USSR50th Anniversary Udmurt State University]. Izhevsk, 2, 219-224.

Medushevskii, V.V. (2015). Zhanrovaya teoriya $v$ izmerenii krasoty [The theory of genres in the dimension of beauty], In Tridtsat tri etyuda o muzyke: Liber amicorum [Thirty three pieces on music: Liber amicorum, a collection of articles]. Yekaterinburg, M. P. Mussorgsky Ural State Conservatory, $8-16$.

Naiko, N.M. (2019). Zhanrovye kody Diptikh-simfonii Olega Meremkulova [Genre codes of the Diptych Symphony by Oleg Meremkulov]. Khudozhestvennye traditsii Sibiri: Materialy mezhdunarodnoi nauchnoi konferentsii 2-3 okyabrya 2018 goda [Artistic traditions in Siberia - Proc. International Science Conference on 2-3 October 2018]. Krasnoyarsk, Dmitri Hvorostovsky Siberian State Academy of Arts, 299-306.

Naiko, N.M. (2020). Pamyati netlennyi sled. K vosmidesyatipyatiletiyu O. O. Meremkulova [The undying trace of memory. For O. O. Meremkulov's 85th birthday]. Khudozhestvennye traditsii Sibiri: materialy III Mezhdunarodnoi nauchnoi konferentsii 12-13 noyabrya 2020, Dmitri Hvorostovsky Siberian State University of Arts, red. N. V. Perepich [Artistic traditions in Siberia - Proc. 3d International Science Conference on 12-13 November 2020, Dmitri Hvorostovsky Siberian State Academy of Arts, edited by N. V. Perepich]. Krasnoyarsk, Dmitri Hvorostovsky Siberian State Academy of Arts, 132-136. 
Serebryakova, L. (2017). V poiskakh obretayemogo smysla. Russkaya muzyka v dvizhenii vremeni [In search of obtained meaning. Russian music in the flow of time]. Moscow, Agraf, $560 \mathrm{p}$.

Starcheus, M.S. (2012). Lichnost muzykanta [The Personality of the Musician]. Moskva, Moskovskaya gosudarstvennaya konservatoriya im. P.I.CHajkovskogo, $846 \mathrm{p}$.

Jung, C.G. (1998). O stanovlenii lichnosti [The Development of Personality] In Karl Gustav Yung Bog i bessoznatel'noe. [God and the Unconscious] Moskva, Olimp, 454-477. 